\title{
Calcineurin Subunit B Type 2
}

National Cancer Institute

\section{Source}

National Cancer Institute. Calcineurin Subunit B Type 2. NCI Thesaurus. Code C38531.

Calcineurin subunit B type $2(170 \mathrm{aa}, \sim 20 \mathrm{kDa})$ is encoded by the human PPP3R2 gene.

This protein is involved in both protein dephosphorylation and osteoblast differentiation. 